\title{
Globalization and Consumption Patterns among the OECD Countries*
}

\author{
István Kónya ${ }^{\dagger}$ and Hiroshi Ohashił
}

\begin{abstract}
The paper examines the evolution of consumption patterns in Organization for Economic Co-operation and Development (OECD) countries from 1985 to 1999. Estimation of demand function parameters uncovered consistent evidence that differences in consumption patterns have recently diminished between the countries. The paper further uncovers an empirical relationship that indicates that increased bilateral trade and foreign direct investment (FDI) has contributed to the convergence of consumption patterns. The result is robust to the consideration of endogeneity in the trade and FDI variables.
\end{abstract}

JEL: C33, D12, F02

Keywords: Globalization, almost ideal demand system, endogeneity, convergence

\section{Introduction}

The international integration of markets for goods and services characterizes the modern world economy. This process - commonly known as "globalization" - is providing more and more countries with opportunities to enjoy higher standards of living, but at the same time is placing pressure on societies to alter their traditional practices (These tensions are discussed in Rodrik, 1994). Economic questions related to globalization have been extensively analyzed. Income convergence is an issue that has recently been intensively examined, and current and historical evidence (Fisher,

${ }^{*}$ We thank Leslie Hannah, Isao Ishida and Kiminori Matsuyama for comments, and Keiji Sato and Yoto Yotov for excellent research assistance. Konya acknowledges the financial support provided by the Richard W. Tresch Junior Faculty Fund of the Department of Economics, Boston College.

${ }^{\dagger}$ Department of Economics, Boston College. 140 Commonwealth Av, Chestnut Hill MA, USA. Fax: 617-552-2308. E-mail: konya@bc.edu

${ }_{\ddagger}^{\ddagger}$ Department of Economics, University of Tokyo. 7-3-1 Hongo Bunkyo Tokyo 113-0033 Japan. Fax: +81-1-3-5841-5521. E-mail: ohashi@e.u-tokyo.ac.jp 
2003; Williamson, 1996) indicates that income differences diminish with the progress of globalization, ${ }^{1}$ at least for countries that participate in the process.

Some point out another influence of globalization: Globalization makes consumption behavior increasingly similar from one country to another. Critics of globalization often argue that the powerful force of market integration is driving the world toward increasing homogeneity (e.g., Spring, 2000). This is because, according to their claim, multinational corporations abuse their global market power to stifle local variation, denying consumers access to products other than their own. This, in turn, alters traditional practices, irrevocably homogenizing the world's needs and desires. This view was manifested in the infamous act of French farmer José Bové who drove his tractor into a local McDonald's to protest against the multinational.

Although criticisms of globalization often reflect a view of the world that economists generally do not share, it is interesting to note that the critics' point about the increasing homogeneity of preference structure around the world has also been discussed in academic circles. Theodore Levitt's widely cited article (Levitt, 1983), "The Globalization of Markets", argues that firms should sell standardized consumer products, because "the world's preference structure is relentlessly homogenized":

Different cultural preferences, national tastes and standards, and business institutions are vestiges of the past. Some inheritances die gradually; others prosper and expand into mainstream global preferences. So-called ethnic markets are a good example. Chinese food, pita bread, country and western music, pizza, and jazz are everywhere. They are market segments that exist in worldwide proportions. They don't deny or contradict global homogenization but confirm it (96-97).

On the other hand, there are anecdotes illustrating the existence of distinctive local preferences, and significant international differences in consumption behavior. ${ }^{2}$ The

\footnotetext{
1 This reading of the evidence has been challenged by Rodriguez and Rodrik (2001), who claim that countries benefit little from increased openness.

2 The experience of Tyco Toys in Europe provides an interesting illustration (quoted by Head, 2004. The original citation is in the Wall Street Journal, September 26, 1996: R8):

For Mr. Austin [director of Tyco's European operations], the final straw came in October 1992, when he and Mr. Grey (CEO of Tyco) clashed over whether Matchbox should produce action figures and toy vehicles in Britain tied to a planned sequel for 'Thunderbirds', a popular children's science-fiction TV show. At the time, Thunderbird items were Matchbox's most profitable European brand.
} 
literature on learning by exporting, for example, hypothesizes that exporting firms become more productive precisely because they tend to be exposed to knowledge of local tastes in foreign countries, knowledge unavailable to firms whose operations are confined to the domestic market (Clerides, Lach, and Tybout, 1998; Salomon and Shaver, 2003).

The purpose of this paper is to investigate whether or not countries' consumption patterns are indeed converging. The paper focuses on countries in the Organization for Economic Co-operation and Development (OECD) in the period between 1985 and 1999. This is the first paper to attempt to provide systematic evidence pertaining to international consumption patterns, which is an important part of the globalization debate. The paper finds evidence of the existence of homogenization of consumption behavior in the OECD, especially for the period after 1993.

Section 2 of this paper begins by examining changes in the expenditure shares of major household consumption items in the OECD countries. Statistical analysis indicates that these expenditure shares have became more similar to one another over the study period. Section 3 then identifies the economic forces driving these changes in international consumption patterns; in particular, we consider the role of prices and income. To analyze the effect of price and income, we make estimates based on the flexible demand system proposed by Deaton and Muellbauer (1980). While these two monetary factors explain a good deal of the variation in expenditure shares, a nonmonetary factor, reflected in the demand residual, also shows a systematic pattern of mean reversion. This observation implies that the residual from the demand estimation also contributes to the homogenization of the international consumption pattern.

Nonetheless, it is not clear what explains the remaining variation in the consumption patterns after prices and income are accounted for. The demand residual may contain measurement error, and permanent as well as temporary shocks that influence people's consumption patterns. We use a factor analysis method in Section 4 , in an effort to distinguish these three elements in the residual. The factor analysis reveals that the permanent component accounts satisfactorily for consumption behavior. Under some functional restrictions, we argue, among other possible hy-

"The line Dick Grey gave to me was, 'We aren't going to do local development because Tyco preferred to promote global brands'", Mr. Austin recollects. "I said, 'What if a local development makes money?' He said, 'Read my lips.'” Mr. Austin abruptly quit, formed a toy business - and reaped 12 millions in sales and 4 million in profit peddling the Thunderbird sequel's product line the following year. 
potheses, that the permanent component in the demand residual contains countries' preference information, and thus the mean reversion observed in the component may indicate that consumer preferences are indeed becoming homogenized in the OECD.

An interesting question concerns the mechanisms through which preferences evolve. Discussion of globalization often hypothesizes that exposure to and acquaintance with other cultures through various channels of interaction influences people's habits and consumption patterns (see, e.g., Yasuf, 2001). This hypothesis is similar in spirit to that proposed by Becker and Stigler (1977): As two countries interact through exporting and importing goods and services, foreign direct investment, or immigration, their consumption habits may influence each other. Tourism, and trade in cultural goods, such as movies, music, and books, for example, would obviously influence people's habits and consumption patterns. It is an empirical question whether the consumption behavior of two countries becomes more similar as a consequence of increased interaction.

To gain insight into this hypothesis, we estimate the effects of international trade and foreign direct investment (FDI) on the differences in the demand residuals for pairs of countries. The choice of the dependent variable in this regression is based on the results of our prior analysis, which suggests that the estimated demand error reflects people's preferences. We are interested in the causal relations between trade and FDI, and preference change, but are also concerned about a reverse causality in that, for example, similar preferences between countries may induce more trade and FDI. To protect against this potential endogeneity of trade and FDI, we have adopted an estimation procedure devised by Frankel and Romer (1999). We find that countries engaging in more trade and FDI experience convergence in preferences, measured in terms of the demand residuals. As the theory predicts, the ordinary least squared estimates of trade and FDI are smaller than the two-stage least squared estimates. The results provide an extension to the findings reported in the literature on international knowledge spillovers (surveyed in Keller, 2004): International trade and foreign direct investment are important vehicles of knowledge transfer, not only on the production side (as previous research has shown), but also on the consumption side. Section 5 concludes the paper, and is followed by data and technical appendices.

Before turning to the next section, we briefly discuss some caveats in interpreting the results in the paper. The scope of the paper's analysis is limited by data quality at two levels. First, we are dealing with country-level data, so our demand 
estimation cannot incorporate variables that reflect heterogeneity in household characteristics within a country. Second, our data pertain to aggregated household consumption goods. This aggregation method makes it difficult to make an international comparison of product attributes. Although it abstracts from heterogeneity in household and product characteristics, the OECD data used in the paper are best suited for the analysis among the publicly available data. This paper conducts the first international comparison of consumption behavior using this publicly available data set.

\section{Preliminary Analysis of Expenditure Patterns}

This section briefly describes the data set used in the paper and provides some preliminary evidence regarding consumption behavior. A more detailed description of the data construction appears in Appendix A. The data source used is Purchasing Power Parities and Real Expenditures, published by the OECD in 1985 (22), 1990 (24), 1993 (24), 1996 (32), and 1999 (43) (the number of member countries covered in the data in each year's edition is indicated within parentheses). To utilize the full sample period, we have focused on the 22 countries for which data are available in every edition since 1985. As detailed in the appendices, since some data series for Luxembourg are merged with those of Belgium, we have treated these two countries as one in the analysis, and have 21 observations in the data set.

The data were compiled for making international comparisons of GDP from the expenditure side. Final expenditure on GDP is broken down into a group of similar well-defined products. We have focused on household final consumption expenditure, which is decomposed into eight broad categories. ${ }^{3}$ The paper uses two data series: real final expenditure on GDP at international prices as a percentage of GDP, and relative price levels of final expenditure on GDP at international prices $(\mathrm{OECD}=100)$. Both data are measured per capita.

We examine the behavior of differences in expenditure shares between countries over time, to determine whether there is any noticeable evidence of convergence among them. Let $w_{i j t}$ be the expenditure share of product $j$ at country $i$ in period $t$. Note that $t$ could be any of the OECD data publication years: 1985, 1990, 1993, 1996, and 1999. We sometimes omit the time subscript unless there is confusion.

\footnotetext{
${ }^{3}$ Food, beverages and tobacco (11), clothing and footwear (12), gross rents, fuel, and power (13), household equipment and operation (14), medical and health care (15), transport and communication (16), education, recreation, and culture (17), and miscellaneous goods and services (18). The number within parentheses indicates a group number in the OECD data.
} 
To investigate convergence in the expenditure shares, we use two different analytical methods. One method is nonparametric: We plot the value of variance of $w_{i j}$ over time, and examine the change in dispersion among the countries. The other method is parametric: We impose a functional form on the $w_{i j}$-convergence process, and estimate the magnitude of convergence or divergence of $w_{i j}$ values.

The results used by the first method are in Figure 1. The graph presents two standard errors of the distribution of $w_{i j}$ over time, averaged across the products, $j .{ }^{4}$ The dotted line shows the average standard errors for the G-7 countries (Canada, France, Germany, Italy, Japan, the U.K., and the U.S.), while the solid line shows the average of all 21 examined countries. Note that the value of $w_{i j}$ lies between zero and one. It makes sense that the variance of the entire sample should be larger than that of a subset of the sample. In general, we observe a declining trend in both standard error measures throughout the period: the average rate of decline is 7.4 (15.3) percent for the pooled sample, and 5.4 (17.3) percent for the G-7. The numbers within the parentheses are the average rate of decline, excluding the 1990-1993 period.

To check the results in the figure analytically, we test the expenditure share convergence using the following $\mathrm{AR}(1)$ specification:

$$
z_{i j t}=\phi_{j} z_{i j t-1}+\nu_{i j t}
$$

where $z_{i j t} \equiv w_{i j t}-\overline{w_{j t}}$, and $\overline{w_{j t}}$ is the average of expenditure shares for product $j$ at time $t$ for all the countries; $\nu$ is independent "white noise". This convergence measure is often used in the literature on income convergence (e.g., Ben-David, 1996) and exchange rates (e.g., Taylor, 2001). We estimate the convergence coefficient for product $j$ to be $\phi_{j}$. No constant term in (1) is required because we have pooled all countries in the sample. If $z_{i j t}$ is non-stationary (i.e., $I(1)$ ), we cannot make a direct inference to convergence based on the ordinary least squared (OLS) estimate of (1). To obtain an appropriate measure of $\phi_{j}$, we run the Dickey-Fuller test for (1).

Table 1 shows the OLS estimation results of (1) for each of the seven products (because the sum of the shares is one, we drop the result of the first product from the table). We run regressions for G-7 and for the OECD countries separately. The results indicate the existence of convergence in $z_{j}$. The average $\phi_{j}$ estimate is approximately 0.7 , and the 95-percent confidence interval lies in the unit interval

\footnotetext{
${ }^{4}$ We show the figure for this average for expositional purposes, but our discussion below holds when we look at changes in expenditure shares by product.
} 
for all cases. The number of periods it takes for the expenditure shares to be cut in half is given by $\log (0.5) / \log \left(\phi_{j}\right)$. This half-life index is calculated to average 2.2 for the OECD, which is roughly equivalent to 7 years.

The table also lists two DF test statistics. One is the Dickey-Fuller $t$ test $\left(D F_{t}\right)$, and the other is the Dickey-Fuller $\rho$ test $\left(D F_{\rho}\right)$. We reject the null hypothesis that the process is the unit root for all the products in the OECD, and for a few products in the G-7. Given the well-documented suspicion that DF tests have low power in small finite samples (Hayashi, 2000), we take our results as indicating that $z_{i j}$ is stationary among the OECD.

\section{Demand Analysis}

The previous section analyzed changes in expenditure shares between the OECD countries, and found evidence of convergence during the study period. The analysis, however, passed over essential factors, such as prices and income, that influence the product expenditure shares. This section incorporates these factors in an analytical framework. In particular, we introduce a demand model to control for prices and income in studying expenditure shares. Once we have controlled for prices and income, Section examines the remaining variation in the expenditure shares.

\subsection{Estimation Framework}

This section uses demand function estimation to identify economic factors that drive the convergence of the expenditure shares. Standard microeconomics suggests that two factors, prices and income, are important in explaining variation in expenditure share. This section estimates a linear approximation of Deaton and Muellbauer's (1980) almost ideal demand system (AIDS). The AIDS model is useful, because it provides a local first-order approximation to any true demand system, whether derived from the theory of choice or not.

Ideally, we would have liked to estimate demand separately for each country and for each year, and to investigate whether any of the country-level demands converged over the study period. The data requirements of this approach are, however, severe: It would require data on intracountry variation, such as household-level consumption data by country for each year, and such a rich data set is not currently available for the OECD countries. We instead took a different approach to tackling the convergence problem. We characterized a representative country's demand using 
the AIDS model, and analyzed the distance between the estimated representative demand and each country's observed demand.

The AIDS share equations for good $j$ at country $i$ at time $t$ are given by:

$$
w_{i j t}=\alpha_{j}+\sum_{s=1}^{n} \gamma_{j s} \ln \left(p_{i s t}\right)+\beta_{j} \ln \left(\frac{m_{i t}}{k_{i t} Q_{i t}}\right)+\varepsilon_{i j t},
$$

where $m_{i t}$ is total expenditure on the products under study. The literature often use this variable as the measure of income. An aggregate price index is defined as $Q_{i t}$. We use the Stone price index for this variable: $\ln \left(Q_{i t}\right)=\sum_{k=1}^{n} w_{k t} \ln \left(p_{i k t}\right)$, where $p_{i k t}$ is the price of product $k$ in country $i$ at time $t$. The error of the model is $\varepsilon_{i j t}$. Parameter $k_{i t}$ is interpreted as a measure of country size, which, in principle, considers age composition and other households characteristics in country $i$ at any given time $t$. Deaton and Muellbauer (1980) discusses that this parameter reflects not only taste variation but the demographic structure across countries. Data limitations, however, prevent us from modeling the variation of $k_{i t}$ with country and household characteristics in the empirical implementation. To the extent that $k_{i t}$ is either constant or independent of $m_{i t}$ and $p_{i s t}$, no omitted variable bias arises, and the constant in the AIDS demand can be relabeled as $\alpha_{j}-\beta_{j} \log \left(k_{i t}\right)$. We make this assumption pertaining to $k_{i t}$ in the estimation. Deaton and Muellbauer (1980) also points out that $\alpha_{j}$ and $\gamma_{j s}$ can differ by country without altering the representative consumer hypothesis embodied in (2). The parameters, $\alpha_{j}$ and $\gamma_{j s}$ in (2), are, in this case, weighted averages of the micro parameters of country's household demand functions.

To derive the demand function (2), we assume that the countries face the same choice set defined over the eight aggregated product categories mentioned above. In studying the microeconometric household behavior of a particular country, it might be important to seek product data which is more disaggregated and which incorporates product attributes. Such a data set is not currently available for the OECD countries. Among the publicly available data, the data used in the paper are the best suited for the analysis of international comparisons of aggregate consumption behavior. We view our present work as a starting point for the further examination of international comparisons of consumption behavior, and we leave improvements in data quality to future research.

The principle of utility maximization implies the following three restrictions: (a) the adding up constraint requires that $\sum_{j} \alpha_{j}=1, \sum_{j} \beta_{j}=0$, and $\sum_{j} \gamma_{j r}=0$; (b) homogeneity of demand requires that $\sum_{r} \gamma_{j r}=0$; (c) symmetry requires that 
$\gamma_{j r}=\gamma_{r j}$, and involves cross equation restrictions requiring that the equations be estimated as a system. Unrestricted estimation of the model automatically satisfies (a), while both (b) and (c) can be easily imposed and tested. Even if maximizing behavior is not assumed, but it is simply held that demands are continuous functions of the budget and of prices, the AIDS demand functions without the restrictions can still provide a first-order approximation to any true demand system.

We are interested in whether expenditure shares in different countries converge between countries, after controlling for the product fixed effect (the first term in the left-hand side of (2)), the own- and cross-price effects (the second term), and the income effect (the last term of (2)). In other words, we examine whether both income and prices can by themselves explain the observed convergence in expenditure shares.

\subsection{Demand Estimates}

This subsection describes estimation results of the linearized AIDS model (2) using the OECD data. The demand system involves seemingly unrelated regressions (SUR), but since the regressors are the same for all product categories, the generalized least square estimator for the unrestricted model reduces to the application of OLS to each equation separately. As discussed in the previous section, we assume that $k_{i t}$ is either constant or independent of $m_{i t}$ and $p_{i s t}$. Thus the constant term in (2) should absorb the variation in $k_{i t}$.

Table 2 shows summary statistics: information on goodness of fit and serial correlation for the estimation, with and without the restrictions implied by the imposition of demand theory. In the estimation of a restricted AIDS, one equation must be deleted to avoid singularity, and in this case, we omit miscellaneous goods and services. The parameters of the deleted equation are recovered using the parameter constraints discussed in the previous section. The errors for the deleted equation are then calculated.

The values for $R^{2}$ indicate that each demand system does a modest job in explaining variation of expenditure shares. The unrestricted demands obtain higher $R^{2}$ 's than do the restricted demands. The table also gives Durbin-Watson (D-W) statistics, and F-tests for the validity of the homogeneity condition for each equation. The D-W statistic is an average of the D-W statistics obtained by country for each product category. Deaton and Muellbauer (1980) note in their analysis of postwar British expenditure data, that the imposition of homogeneity generates 
positive correlation in the residuals. This observation leads them to suspect that the rejection of homogeneity may be caused by the inappropriate specification of the dynamic behavior. The results presented in Table 2 do not raise such a concern, although there is a mild drop in the Durbin-Watson statistics for those products where homogeneity is rejected in the OECD data, i.e., clothing and footwear, and miscellaneous goods and services. This result may suggest the converse proposition: that the rejection of homogeneity is not necessarily caused by an inappropriate specification of the demand system.

Since we have eight products in the demand system, the number of estimates totals 80 for the unrestricted model, and 70 for the restricted model. To save space, we do not show the demand estimates. ${ }^{5}$ In the unrestricted case with the OECD data, $\frac{33}{80}$ of the demand system parameters are statistically significant at the 5 percent level; for the restricted specification, $\frac{34}{70}$ are significant.

One issue in the AIDS estimation is whether the restrictions implied by demand theory - i.e., (a), (b), and (c) listed in Section 3.1 - hold. Wald tests indicate that with use of the OECD data, homogeneity is rejected for 3 of the 8 equations at the 5-percent level, and for only 1 equation at the 1 -percent level. The joint test of symmetry rejects the null hypothesis, but the test statistic is not very high. We thus take the unrestricted AIDS estimates as the baseline. ${ }^{6}$ The estimation results show that the two variables, income and price, explain a significant portion of the variation of expenditure shares in the OECD as a whole.

To check whether other factors drive the consumption convergence, we now analyze the estimated residual generated from the AIDS estimates. We use an $\mathrm{AR}(1)$ specification in (1) to check the mean reversion in the residual, $\widehat{\varepsilon_{i j t}}$. Table 3 presents the estimation results of the DF tests; note that because the sum of the residuals is zero in (2), we drop the result of the first product from the table. We add the superscript $\varepsilon$ to the estimated coefficients appearing in the table to distinguish them from the other estimates discussed in previous sections.

We find that the residuals are stationary for the OECD, and mostly stationary for the G-7 countries by either of the DF measures. The convergence coefficient, $\phi^{\varepsilon}$, averages 0.50 , and the half-life index is calculated to be 1.14 ; that is, it would take about 4.5 years for the residual deviation to halve. This convergence rate is about

\footnotetext{
${ }^{5}$ The estimates of the demand system with and without the restrictions are available upon request.

6 The joint statistic for homogeneity is $3.70\left(F_{28,95}\right)$. We checked that results used with the restricted estimates are qualitatively the same as those presented in the rest of the paper.
} 
1.7 times faster than that found in the expenditure share in Table 1. Thus, while income and prices are important determinants in explaining consumption behavior, they cannot solely explain the observed convergence in expenditure shares. The next section performs a detailed analysis of the residuals to seek further insight into this issue.

\section{Further Analysis of Demand in the Convergence of Consumption Patterns}

The above results presented evidence of convergence in the demand residual, after controlling for price and income in the demand system. This section considers economic explanations for this result.

At first glance, the previous section's finding appears to support the hypothesis that preferences in household consumption are becoming homogenized across countries. This hypothesis is similar to the claim of Levitt (1983), and to the criticism of globalization presented in Section 1. It is very difficult, however, to test the validity of the hypothesis, because changes in the preference structure are inherently unobservable, and proxy variables that capture such changes are hard to come by. We thus need to impose a reasonable functional form on the residual structure to obtain further economic insight into the issue. This section implements an extension of factor analysis methods in an attempt to test the hypothesis of convergence in preference structure. Factor analysis methods have been used in various empirical works, including those of Goldberger (1974) and Hyslop (2001).

The demand residual contains not only information on fundamental preferences, but also on other "noises" caused by measurement problems and misspecification in the demand function. We thus decompose the demand residual into a preference component and remaining noise. The preference component, if successfully estimated, would tell us the validity of the preference-convergence hypothesis. Section 4.1 uses factor analysis methods to find empirical evidence supporting the hypothesis that fundamental attributes of preference have been converging across the OECD since 1993. Based on this finding, Section 4.2 considers economic factors that drive the international convergence in preferences.

\subsection{Factor Analysis Methods}

This subsection examines the residual obtained from the AIDS model (2). The previous section analyzed the statistical property of the residuals and found evidence 
of convergence. This section imposes a functional form on the structure of the residual, and tries to uncover a taste component in the residual apart from the other components.

As the first step, let us assume that the demand residual comprises two components: a country-specific persistence component $\left(\alpha_{i}\right)$, and a transitory component $\left(u_{i j t}\right)$ :

$$
\epsilon_{i j t} \equiv \alpha_{i}+u_{i j t}
$$

The permanent component can be interpreted as reflecting the effect of those factors that a representative consumer in country $i$ regards as determining the fundamental attributes of preferences. ${ }^{7}$ It is analogous to the expected value of a taste distribution, $\epsilon_{i j t}$. The transitory component is to be interpreted as reflecting all other factors that are likely to be treated by a representative consumer in affected country $i$ as "accidental" occurrences. Note that the transitory component may be correlated over time.

The immediate problem with specification (3) in studying preference convergence is that the permanent component cannot play any role in the converging process, and nonstationarity is caused only by the transitory component. However, as discussed in Section 1, we are interested in the hypothesis that a recent trend of convergence in consumption patterns may be attributable to the role of the persistent preference component. We borrow a technique from factor analysis methods, and use a simple modification of (3) to produce:

$$
\epsilon_{i j t} \equiv \theta_{t} \alpha_{i}+\varphi_{t} u_{i j t}+\eta_{i j t}
$$

where $\theta_{t}$ and $\varphi_{t}$ are year-specific factor loadings on the permanent and transitory components, respectively.

Assuming that the variances of $u_{i j t}$ and $\eta_{i j t}$ are constant over time, permanent and transitory components of the variance expand or contract in this specification according to the values of the scale factors, $\theta_{t}$ and $\varphi_{t}$. We impose the following assumptions in specification (4), similar to the ones made in Hyslop(2001): the transitory component is assumed to follow a first-order autoregressive process, and the specification is written as $u_{i j t}=\rho u_{i j t-1}+v_{i j t}$ with innovation $v_{i j t}$. Unrestricted time-varying factor loading on each of the permanent and transitory components provides a flexible specification of nonstationarity in demand residuals. Finally, $\eta_{i j t}$

\footnotetext{
7 This model assumes a single index of preference, and thus different dimensions of preference change proportionally over time.
} 
represents a measurement error in demand, which is assumed to be uncorrelated across time.

For identification purposes, $\alpha_{i}, u_{i j t}$ and $\eta_{i j t}$ are assumed to be mutually orthogonal, with $E\left(\alpha_{i}\right)=E\left(u_{i t}\right)=E\left(\eta_{i j t}\right)=0$. The initial period loading factors, $\theta_{1}$ and $\varphi_{1}$ are normalized to unity. The cross-sectional variance in the residual is thus given by:

$$
\operatorname{Var}\left(\epsilon_{i j t}\right)=\operatorname{Var}\left(\theta_{t} \alpha_{i}\right)+\frac{\varphi_{t}^{2}}{1-\rho^{2}} \operatorname{Var}\left(v_{i j t}\right)+\operatorname{Var}\left(\eta_{i j t}\right) .
$$

The loading factor on the permanent component measures the extent of preference homogenization across countries. The permanent taste inequality is $\theta_{t}$, and the factor, $\operatorname{Var}\left(\alpha_{i}\right)$, captures the extent of the inequality: If the permanent taste inequality becomes wider, $\theta_{t}$ values will be estimated larger over time. The decrease in the estimated $\theta_{t}$ values is evidence of the progress of taste convergence across countries.

Model (4) is estimated using the generalized method of moments (GMM), minimizing a sum of squared differences between the theoretical covariance matrix of demand and the sample covariance matrix. Details of the estimation method are described in Appendix B.

Table 3 summarizes the results of estimating (4) using the OECD data. The goodness-of-fit measure indicates that the specification fits well. The estimated value of $\operatorname{Var}(v)$ is negative, but not significantly different from zero; for convenience we will take the value to be zero in the following analysis. The variance estimates imply that, at the beginning of the sample, about 30 percent of the variance in the demand residual is attributable to the permanent factor. We do not find much persistence in the transitory components, the correlation coefficients being estimated to be 0.07 .

Many of the loading factors on the transitory components are not precisely estimated. A stark difference is observed in the loading factors on the permanent components, where the aggregate result implies that the permanent variance doubled in 1993 to 1.60, and decreased thereafter to 1.11 in 1999.

Overall, our findings in this section support the hypothesis of preference convergence, as captured by the permanent component, at least in the period after 1993. To identify what products are responsible for the increase in $\theta_{t}$ in the period from 1990 to 1993, we returned to the original values of the demand residual, and examined the changes in the standard error of the residual by product. We found that three product categories mainly account for the divergence in $\epsilon_{i j}$ : gross rents, 
fuel, and power (13); medical and health care (15); and miscellaneous goods and services (18). The consumption pattern of these products, the first two in particular, have been susceptible to rises in housing prices and changes in age structure, factors unaccounted for in the estimation procedure. Excluding these products from the estimation strengthens the consumption pattern convergence as found in this section.

\subsection{Role of Trade and FDI}

Section 3 argued that prices and income do not entirely explain the consumption pattern in the demand estimation. The factor analysis method revealed that the permanent component plays a role in expenditure share convergence in the period from 1993 to 1999. The permanent component represents fundamental attributes of preference of a representative consumer in a country. Based on the finding from the previous section, this section investigates what economic factors cause the convergence in preference between OECD countries, through the analysis of the demand residual.

Three channels are instrumental: international trade, foreign direct investment (FDI), and immigration. Grossman and Helpman (1993) argue that trade facilitates the bi-directional exchange of knowledge across borders. Through interaction with foreign goods and services, people are exposed to new knowledge not available to those who are confined to an autarkic economy. Interacting with people from other countries also facilitates information flow to host countries. We conjecture that the new knowledge acquired through these international channels affects consumption patterns in host countries. One can think of this mechanism as an application of Becker and Stigler's (1977) idea, in that peoples' consumption pattern evolves as the output of home production, and that an input fed into the production is the new knowledge obtained by international interactions. While we cannot directly estimate such a Becker-type production function, if the international interaction provides new knowledge that is sufficient to result in a change of consumption pattern in the host countries, we should be able to identify it empirically.

We focus on the bilateral relationships between countries, and examine whether the difference between their consumption patterns, conditional on price and income, is affected by the influences of the three channels. Due to the severe lack of immigration data, ${ }^{8}$ this paper focuses solely on the impact of international trade and

\footnotetext{
${ }^{8}$ The immigration data are from Trends in International Migration (2000 and 2003 editions).
} 
foreign direct investment on the difference in the consumption patterns.

The difference in consumption pattern between countries $k$ and $l$ at time $t$, conditional on price and income, is provided by $\epsilon_{k, t}-\epsilon_{l, t} \equiv D \epsilon_{k l, t}$. We analyze this variable using bilateral trade flows (the sum of exports and imports) and FDI flows (the sum of incoming and outgoing investment). ${ }^{9}$ Both variables are expressed logarithmically. Because it takes time before trade and FDI flows affect the consumption pattern, we use lags of the trade and FDI variables, Trade $k_{k l, s_{t}}$ and $F D I_{k l, s_{t}}$, where $s_{t}$ is the period for which we calculate averages of the lagged variables. For each $t=1985,1990,1993,1996$, and 1999, $s_{t}$ indicates the respective period, 19801984, 1985-1989, 1990-1992, 1993-1995, and 1996-1998, for which we use the average amounts of trade and FDI flows. Use of the averaged variables would also alleviate possible bias in the estimates caused by short-term fluctuations of trade and FDI activities.

We estimate fixed and random effects models to control for the effect that is specific to bilateral country pairs:

$$
D \varepsilon_{k l, t}=a_{0}+a_{1} \cdot \operatorname{Trade}_{k l, s_{t}}+a_{2} F D I_{k l, s_{t}}+b_{k l}+\varsigma_{k l, t}
$$

where $b_{k l}$ is an time-invariant individual effect, and $\varsigma_{k l, t}$ is the remaining regression error. We have 21 country observations in our sample. The number of full bilateral combinations is thus 210 per year. The trade data are five-year balanced panel (1050), but the FDI data are missing for some countries and years (491). The number of observations is indicated within parentheses.

We will now investigate the impact of trade and FDI on the consumption pattern captured in (5). Since we use a lag in constructing the trade and FDI variables, the current shock, $\varsigma_{k l, t}$, should not affect the variables determined in the past. However the averaged lagged trade and FDI variables may not be exogenous, if $\varsigma_{k l, t}$ has a serial correlation. In particular, we are concerned that the change in consumption pattern may influence trade and FDI volumes. It is probable that countries with similar preference structures would trade more, because, for example, it saves firms from having to tailor their products to meet the specific needs of foreign customers. It is not clear, however, how FDI flows would be affected by this reverse causation. The direction of the effect on FDI depends on what economic factors drive FDI

The data contain citizenship information, but lack country-of-origin data for many countries that we need to examine for the study. The country-of-origin data are available only for 88 observations of a total of 1050 bilateral relationships, leading us to abandon the data in this study.

9 The FDI stock data are not consistently available for the OECD countries. 
activity. On one hand, if the main purpose of FDI is for firms to learn local information to customize their products for foreign markets, bi-directional FDI would decrease as countries developed more similar preferences. On the other hand, if firms establish a physical presence in host countries to benefit from Marshallian locational externalities, the FDI flows would increase between the countries that consume products with similar characteristics.

To protect against possible endogeneity, we have borrowed an idea from the literature on the gravity equation (e.g., Frankel and Romer, 1999), and have constructed appropriate instruments. The gravity equation relates countries' bilateral trade and FDI flows with measures of their economic potential, such as GDP, and various measures of trade and FDI costs. We use five variables in relation to the trade and FDI costs: sizes of GDP and population, distance between the countries (logarithmically expressed), whether they share a border, and whether they share a language. These variables relating to trade and FDI are presumably uncorrelated with countries' consumption patterns. Note that the values of the last three instruments do not change over time, and thus we can only use them in the random effect estimation.

Table 5 shows the estimation results. The table presents three major specifications: model (A) only includes the trade variable in (5), (B) contains only the FDI variable, and $(\mathrm{C})$ includes both variables. The Hausman specification test rejects the null hypothesis that coefficients estimated from the random effect model are consistent; furthermore, the estimated coefficients of trade and FDI are not significantly different from zero in most cases. We thus report only the fixed effect estimates in Table 5 with the OLS and the two-stage least squared (2SLS) methods. Note that the FDI data contains missing observations, and that samples used in (B) and (C) are less than half the size of the sample used in (A). The table reports that both the trade and FDI variables are precisely estimated in $(\mathrm{A})$ and $(\mathrm{B})$, but generate large standard errors in the case of $(\mathrm{C})$. The imprecise estimates are largely due to the smaller number of observations, which generates a moderately high correlation between the trade and FDI variables (0.7). The rest of the section thus mainly focuses on the estimation results of $(\mathrm{A})$ and $(\mathrm{B})$.

Table 5 shows that model (A) fits well, but the other models show poor fits in light of the adjusted $R^{2}$ measure obtained by the OLS estimates. We use a gravity equation in the first-stage regression for the 2SLS methods. The average first-stage F-statistics imply that the instruments are not weak, and the J-statistics (the statis- 
tics for overidentifying restrictions) would reject the hypothesis that the instruments are orthogonal to the error. The J-statistics test the validity of instruments conditional on there being a set of valid instruments that achieve just-identification of the model. The statistic is not calculated for model $(\mathrm{C})$, because the model is just-identified.

The coefficients of both models (A) and (B) are significantly different from zero. The trade and FDI coefficients indicate the impact of a one-percent change in the explanatory variables on the difference in residuals. The OLS estimates in (A) indicate that a one-percent increase of bilateral trade decreases the difference in the consumption pattern between the countries (reflected in the demand errors) by 0.015. The trade volumes among the OECD countries grew by an average annual rate of 13 percent over the study period. In view of the fact that the mean value of $D E$ is 0.098 the annual convergence rate equals half of the standard deviation of $D E$. The OLS estimates in (B) show that a one-percent increase in bilateral FDI flows decreases $D E$ by 0.006 .

We use the 2SLS method to correct for possible bias in the trade and FDI estimates. We expect to find a downward bias in the trade coefficient, because there may be little need to customize products for a foreign market. The direction of the bias in the FDI flow estimate is uncertain. The 2SLS estimates in (A) and (B) show that the bias is corrected in the direction of the successful elimination of the simultaneity bias. The result of the 2SLS trade estimation in (A) is -0.020 , 30 percent lower than the OLS estimate, while the FDI estimate is more than 130 percent lower than that obtained in the OLS estimation. This in turn indicates that the FDI flow is induced by similarity of preferences across countries.

The estimation results in Table 5 support the hypothesis that the consumption pattern (conditional on price and income) converges with an increasing interaction through trade and FDI flows among the OECD countries.

\section{Conclusion}

Both the international integration of markets and the advance of Internet technology have been changing consumption patterns in developed countries. The World Wide Web has taken just five years since its launch in 1989 to reach a global audience of 50 million, and Internet traffic doubles every 100 days. The Internet has transformed lives in developed as well as in developing countries. Now it is easy to obtain information as to what people in other countries eat, drink, and wear. Internet 
retailing makes it easier for us to purchase goods and services from abroad. The Internet thus has facilitated trade in goods, enlarged trade in services, and moved capital flows to a higher level. The purpose of the paper is to examine whether we can observe such effects in consumption data.

This paper represents the first attempt to make an international comparison of the consumption behavior among the twenty-two OECD countries. It used the quantities and prices of eight broadly defined household-consumption goods for each country, whose data source is often used in the OECD purchasing power parity study. The paper examined the aggregated consumption pattern across these countries in the period between 1985 and 1999.

The paper found that the expenditure shares of household consumption goods indeed converged between the industrial countries. While prices and income play an important role in explaining this pattern, these two economic factors do not fully account for the observed convergence in consumption behavior. The evidence shows that the residuals from our demand system estimation display convergence, even after controlling for prices and income. Using factor analysis methods, the paper decomposed the residual into three components: permanent and transitory elements, and measurement error. The estimation result showed that the permanent element, reflecting countries' underlying preferences, converged over time after 1993. This convergence process was estimated to be driven by trade and foreign direct investment.

The paper's results have implications for the ongoing political debate about the effects of globalization. The evidence found in the paper accords with the claim often made by both proponents and opponents of world-wide integration, that countries' consumption patterns become similar with the progress of globalization. While economists tend to take a narrow view and emphasize the benefit of globalization, the paper's results can be interpreted as favoring the view that international convergence in consumption patterns places pressure on societies to alter their traditional practices, and as a result, destabilizes domestic social arrangements. The paper attempted to look at a new aspect of the globalization process, and offer a broader perspective than the one economists usually adopt. We hope that the paper's finding provides a starting point for closing the gap between economists and anti-globalization critics in the future debate. 


\section{References}

[1] Altonji, J.G., and L.Segal., 1996, Small Sample Bias in GMM Estimation of Covariance Structures, Journal of Business and Economic Statistics, 14(3): $353-66$.

[2] Ben-David, D., 1996, Trade and convergence among countries, Journal of International Economics, 40, 279-298.

[3] Deaton, A., Muellbauer, J., 1980, An almost ideal demand system. American Economic Review 70, 312-326.

[4] J.A. Frankel and D. Romer, 1999, Does trade cause growth?, American Economic Review, 89(3), 379-399

[5] Goldberger, A.S., 1974, Unobservable Variables in Economics, in Frontier in Econometrics, Zarembka eds., New York, Academic Press: 193-211.

[6] Grossman,G.M. and E.Helpman, 1993, Innovation and Growth in the Global Economy, Cambridge, MA: MIT Press.

[7] Hayashi, F., 2000, Econometrics, Princeton University Press.

[8] Head, K., 2004, Elements of Multinational Strategy, Mimeo, University of British Columbia, Vancouver BC

[9] Hyslop, D.R., 2001, Rising U.S. Earning Inequality and Family Labor Supply: The Covariance Structure of Intrafamily Earnings, American Economic Review, 91(4), 755-777.

[10] Keller, W., 2004, International Technology Diffusion, Journal of Economic Literature, Forthcoming

[11] Levitt, T., 1983, The Globalization of Markets, Harvard Business Review, May/June 1983: 92-102.

[12] Rodriguez, F. and Rodrik, D., 2001, Trade Policy and Economic Growth: A Skeptic's Guide to the Cross-National Evidence, in Macroeconomics Annual 2000, eds. Ben Bernanke and Kenneth S. Rogoff, MIT Press for NBER, Cambridge, MA. 
[13] Rodrik, D., 1994, Has Globalization Gone Too Far, Institute for International Economics, Washington D.C.

[14] Salomon, R. and J.M. Shaver., 2003, Learning by Exporting: New Insights from Examining Firm Innovation. Working Paper.

[15] Spring, U.O., 2000., Dialogue, Not Clash of Civilization, CRIM/UNAM, Mexico.

[16] Taylor, A., 2001, Potential Pitfalls for the Purchasing-Power-Parity Puzzle? Sampling and Specification Biases in Mean-Reversion Tests of the Law of One Price, Econometrica, 69(2), 473-498.

[17] Williamson, J., 1996, Globalization, Convergence and History, Journal of Economic History, 56(2), 1-30.

[18] Yasuf, S., 2001, Globalization and the Challenge for Developing Countries, World Bank, DECRG.

\section{Appendices}

\section{A Descriptions of the OECD Data}

\section{A.1 Household Consumption Data}

The data used for the demand estimation is from the OECD study entitled Purchasing Power Parities and Real Expenditures. We used all available versions of this study, from the first edition of 1985 to the latest edition of 1999 . This study is published to provide internationally comparable price and volume measures of GDP, and to construct appropriate measures of real income and expenditures covering all the OECD Member Countries. Our data set includes 22 countries (Austria, Australia, Belgium-Luxembourg, Canada, Denmark, Finland, France, Germany, Greece, Ireland, Italy, Japan, New Zealand, Norway, Portugal, Spain, Sweden, The Netherlands, Turkey, the United Kingdom, and the United States) to make the comparison possible across the years from the 1985 to the 1999 editions. Since some data series for Luxembourg are merged with those of Belgium, we have treated these two countries as one in the empirical analysis. 
The paper used two series of the data: one pertaining to real final expenditure on GDP at international prices as a percentage of GDP, the other pertaining to relative price levels of final expenditure on GDP at international prices (OECD $=$ 100). Both data series use per capita measures. ${ }^{10}$ When prices are not reported, we calculated them as the ratio of real and nominal expenditures. We converted the expenditure data into per capita measures when these are not already available. Population data used for the conversion are from the IMF's International Financial Annual Database (October, 2003).

The paper used eight household expenditure categories, listed in footnote $3 .^{11}$ To focus directly on the household consumption pattern, we did not use government consumption and capital formation, operating under the assumption that government spending is exogenous to household decisions on expenditure allocation, and that the saving and consumption decisions are made separately. While it is plausible that household consumption substitutes for government spending and household saving, the assumption claims that this concern affects only the level of household expenditure, but not the expenditure share of each product category.

\section{A.2 Trade and FDI Data}

This appendix describes the data used to estimate (5). There are two explanatory variables in this equation. The Trade variable is constructed as the sum of imports and exports by country and year, and the data come from the IMF's Direction of Trade Statistics (October, 2003). The FDI variable is the sum of the flows of incoming and outgoing foreign direct investment, and the data are available in the OECD's International Direct Investment Statistics Yearbook (1999). The data on the FDI stock for the OECD are not made available consistently for the OECD countries. Note that even with the data on FDI flows, the data are either not available or missing for about half of the bilateral country pairs.

We used five instruments for 2SLS estimates generated with (5): The data on GDP are from the World Bank's World Development Indicators Database (2003), measured in constant 1995 dollars; population data are from the IMF's International Financial Annual Database (October, 2003); the distance measures (in arc distance

\footnotetext{
${ }^{10}$ The paper used data from the following tables: Tables 2.7 and 2.16 for 1985, Tables 2.4 and 2.14 for 1990 and 1993, and Tables A1 and A2 for 1996 and 1999.

${ }^{11}$ Changes in the System of National Account made in 1993 did not affect the classification of the eight product categories listed in footnote 3. They only affect the sub-classification within each of the eight categories.
} 
between the capital cities), the common language indicator, and the common border indicator come from Jon Haveman's International Trade Data website. The last three instruments do not change over time, and were thus used only for random effect estimation.

\section{B Theoretical Covariance Matrix}

This appendix calculates the theoretical covariance matrix, $\Sigma$, used in the GMM estimation. We assume the following error component model (4):

$$
\varepsilon_{i j t} \equiv \theta_{t} \alpha_{i}+\varphi_{t} u_{i t}+\eta_{i j t}
$$

An underlying assumption here is that the product specific effect is already controlled for in the product fixed effect included in the demand estimation of (2). We thus omit the subscript $j$ in this Appendix, unless there is confusion. We assume the existence of a balanced panel structure here, but our discussion is easily extended to an unbalanced structure. Given the above assumption, the theoretical covariance matrix is represented by:

$$
\Sigma \equiv E\left[\varepsilon_{i t} \varepsilon_{i t}^{\prime}\right]
$$

where

$$
\begin{aligned}
\operatorname{Cov}\left(\varepsilon_{i t}, \varepsilon_{h t}\right) & =\operatorname{Cov}\left(\theta_{t} \alpha_{i}+\varphi_{t} u_{i t}+\eta_{i t}, \theta_{t} \alpha_{h}+\varphi_{t} u_{h t}+\eta_{h t}\right) \\
& =0 \text { if } i \neq h \\
\operatorname{Cov}\left(\varepsilon_{i t}, \varepsilon_{h t}\right) & =\operatorname{Var}\left(\theta_{t} \alpha_{i}+\varphi_{t} u_{i t}+\eta_{i t}\right) \\
& =\theta_{t}^{2} \operatorname{Var}(\alpha)+\frac{\varphi_{t}^{2}}{1-\rho^{2}} \operatorname{Var}(v)+\operatorname{Var}(\eta) \text { if } i=h \\
\operatorname{Cov}\left(\varepsilon_{i t}, \varepsilon_{i s}\right) & =\operatorname{Cov}\left(\theta_{t} \alpha_{i}+\varphi_{t} u_{i t}+\eta_{i t}, \theta_{s} \alpha_{i}+\varphi_{s} u_{i s}+\eta_{i s}\right) \\
& =\theta_{t} \theta_{s} \operatorname{Var}(\alpha)+\frac{\varphi_{t} \varphi_{s} \rho^{(t-s)}}{1-\rho^{2}} \operatorname{Var}(v) \text { if } t>s
\end{aligned}
$$

The sample moment is represented by:

$$
S=\frac{1}{M} \sum \widehat{\varepsilon_{i t}} \widehat{\varepsilon_{i t}}
$$

where $M$ is the number of observations. The moment condition is captured by

$$
E(S)=\Sigma
$$


The GMM estimator is obtained by minimizing the following objection function:

$$
\min [\operatorname{vech}(S)-\operatorname{vech}(\Sigma)]^{\prime}[\operatorname{vech}(S)-\operatorname{vech}(\Sigma)]
$$

where "vech" is an operator that transforms a symmetric matrix into a single vector by stacking the unique elements in the columns of the matrix. Altonji and Segal (1996) discuss a small sample bias in the optimal weighting matrix. This paper alternatively used equal weights on the covariance matrix. 
TABLE 1

Convergence in Expenditure Shares

Estimation Results from (2)

\begin{tabular}{|c|c|c|c|c|c|c|c|c|}
\hline \multirow{2}{*}{ Product ID } & \multicolumn{4}{|c|}{ G-7 Countries $(N=28)$} & \multicolumn{4}{|c|}{ All OECD countries $(\mathrm{N}=88)$} \\
\hline & $\Phi$ & $\mathrm{DF}_{\mathrm{t}}$ & $\mathrm{DF}_{\rho}$ & Half-life & $\Phi^{\varepsilon}$ & $\mathrm{DF}_{\mathrm{t}}$ & $\mathrm{DF}_{\rho}$ & Half-life \\
\hline 12 & 0.85 & -1.51 & -4.10 & 4.38 & 0.81 & -3.91 * & -16.61 * & 3.31 \\
\hline 13 & 0.72 & -2.07 & -7.81 & 2.12 & 0.61 & $-4.92 *$ & $-34.48 *$ & 1.39 \\
\hline 14 & 0.81 & -1.87 & -5.23 & 3.35 & 0.74 & $-3.96 *$ & $-22.98 *$ & 2.29 \\
\hline 15 & 0.78 & -2.66 & -6.03 & 2.86 & 0.77 & $-4.59 *$ & $-19.94 *$ & 2.70 \\
\hline 16 & 0.82 & -2.20 & -5.14 & 3.42 & 0.63 & -6.04 * & $-32.49 *$ & 1.50 \\
\hline 17 & 0.73 & -1.97 & -7.60 & 2.19 & 0.80 & $-2.50 *$ & $-17.20 *$ & 3.19 \\
\hline 18 & 0.35 & -3.84 * & $-18.07^{*}$ & 0.67 & 0.58 & $-4.97^{*}$ & $-37.21 *$ & 1.26 \\
\hline Mean & 0.73 & -2.05 & -6.12 & 2.68 & 0.71 & $-4.60 *$ & -25.14 * & 2.22 \\
\hline
\end{tabular}

Note:

The table shows estimation results of the Dicky-Fuller (DF) test (2) for each product. See footnote 3 for reference to product ID.

The tests are run for two cases: one-year $(k=1)$ and two-year $(k=2)$ lags for autoregressors.

The 5-percent critical value for the DF- $\rho$ test $\left(D F_{\rho}\right)$ statistic is -13.3 (with the sample size 50). The 5-percent critical value for

the DF-t test (DFt) statistic is -2.93 . The rejection of the I(1) null by the critical value is indicated by * in each ADF test.

A value in half-life shows the number of period that it takes for expenditure shares to be cut in half, and given by log( 0.5$)$ divided by

the estimated $\Phi$. Notice that one period is roughly equivalent to three years. 
TABLE 2

Goodness-of-fit and D-W statistics for the AIDS estimation (3)

Unrestricted AIDS

R-squared Durbin-Watson Homogeneity Product ID

$11 \quad 0.83$

12

$13 \quad 0.39$

$14 \quad 0.50$

$15 \quad 0.45$

$16 \quad 0.24$

$17 \quad 0.60$

$18 \quad 0.49$

Restricted AIDS

R-squared Durbin-Watson

$\begin{array}{cccc}1.66 & 0.21 & 0.82 & 1.32^{* *} \\ 1.12^{* *} & 4.18^{\star} & 0.49 & 0.71^{* *} \\ 1.28^{* *} & 0.00 & 0.22 & 0.97^{* *} \\ 0.96^{* *} & 3.88 & 0.46 & 0.98^{* *} \\ 0.63^{* *} & 1.18 & 0.38 & 0.64^{* *} \\ 0.93^{* *} & 1.58 & 0.17 & 0.98^{* *} \\ 1.62 & 6.45^{\star} & 0.55 & 1.31^{* *} \\ 1.17^{* *} & 9.59^{* *} & - & 0.92^{* *}\end{array}$

* Significantly different from two at $5 \%$ level

** Significantly different from two at $1 \%$ level

* Significantly different from zero at $5 \%$ level

** Significantly different from zero at $1 \%$ level 
TABLE 3

\section{Convergence in Demand Errors \\ Estimation Results}

\begin{tabular}{|c|c|c|c|c|c|c|c|c|}
\hline \multirow[t]{2}{*}{ Product ID } & \multicolumn{4}{|c|}{ G-7 Countries $(N=28)$} & \multicolumn{4}{|c|}{ All OECD countries $(\mathrm{N}=88)$} \\
\hline & $\Phi^{\varepsilon}$ & $\mathrm{DF}_{\mathrm{t}}^{\varepsilon}$ & $\mathrm{DF}_{\rho}^{\varepsilon}$ & Half-life & $\Phi^{\varepsilon}$ & $\mathrm{DF}_{\mathrm{t}}^{\varepsilon}$ & $\mathrm{DF}_{\mathrm{p}}^{\varepsilon}$ & Half-life \\
\hline 12 & 0.39 & -3.42 * & $-17.01^{*}$ & 0.74 & 0.47 & -5.9 * & -46.48 * & 0.92 \\
\hline 13 & 0.55 & -2.39 & -12.70 & 1.15 & 0.43 & $-6.03 *$ & -50.59 * & 0.81 \\
\hline 14 & 0.60 & -2.62 * & -11.28 & 1.34 & 0.56 & $-4.71 *$ & -38.68 * & 1.20 \\
\hline 15 & 0.74 & -3.03 * & -7.41 & 2.25 & 0.73 & $-4.73^{*}$ & -23.86 * & 2.19 \\
\hline 16 & 0.52 & -3.59 * & $-13.57^{*}$ & 1.05 & 0.55 & $-6.63 *$ & -39.75 * & 1.15 \\
\hline 17 & 0.57 & -2.26 & -11.95 & 1.25 & 0.48 & $-4.70 *$ & -45.62 * & 0.95 \\
\hline 18 & 0.42 & $-3.52 *$ & -16.32 * & 0.79 & 0.44 & $-6.11 *$ & -49.48 * & 0.84 \\
\hline Mean & 0.46 & $-3.40 *$ & $-15.00 *$ & 1.22 & 0.48 & $-6.01 *$ & $-45.69 *$ & 1.06 \\
\hline
\end{tabular}

Note:

The table shows estimation results of the Dicky-Fuller (DF) test (2) for each product. See footnote 3 for reference to product ID.

The tests are run for two cases: one-year $(\mathrm{k}=1)$ and two-year $(\mathrm{k}=2)$ lags for autoregressors.

The 5-percent critical value for the DF-p test $\left(D_{\rho}\right)$ statistic is -13.3 (with the sample size 50$)$. The 5-percent critical value for

the DF-t test (DFt) statistic is -2.93 . The rejection of the I(1) null by the critical value is indicated by * in each ADF test.

$A$ value in half-life shows the number of period that it takes for expenditure shares to be cut in half, and given by $\log (0.5)$ divided by

the estimated $\Phi$. Notice that one period is roughly equivalent to three years. 


\section{TABLE 4}

\section{Factor Analysis Model Estimates}

\begin{tabular}{cccc}
\multicolumn{2}{c}{ Permanent Components } & \multicolumn{2}{c}{ Transitory Components } \\
\hline \hline \multirow{2}{*}{$\operatorname{Var}(\mathrm{a})$} & 2.380 & $\operatorname{Var}(\mathrm{v})$ & -3.921 \\
& $(1.539)$ & $\rho$ & $(12.40)$ \\
& & & 0.07 \\
& & & $(4.14)$ \\
$\theta_{1990}$ & 0.743 & $\varphi_{1990}$ & 1.037 \\
& $(0.087)$ & & $(5.423)$ \\
$\theta_{1993}$ & 1.594 & $\varphi_{1993}$ & 1.786 \\
$\theta_{1996}$ & $(0.240)$ & & $(9.322)$ \\
& 1.475 & $\varphi_{1996}$ & 1.404 \\
$\theta_{1999}$ & $(0.231)$ & & $(7.337)$ \\
& 1.108 & $\varphi_{1999}$ & 1.584 \\
& $(0.206)$ & & $(8.269)$ \\
& & $\operatorname{Var}(\mathrm{n})$ & 6.567 \\
& & & $(5.807)$ \\
\hline \hline
\end{tabular}

Note: $\quad$ For presentation purpose, the estimates and standard errors of theta's and phi's are multiplied by 100,000 .

The standard errors are inside the parentheses. 


\section{TABLE 5}

\section{Explaining the Difference in Countries' Preference}

\section{Fixed Effects Estimates}

\begin{tabular}{|c|c|c|c|c|c|c|}
\hline & \multicolumn{2}{|c|}{ ( A ) } & \multicolumn{2}{|c|}{ ( B ) } & \multicolumn{2}{|c|}{ ( C ) } \\
\hline & OLS & $2 S L S$ & OLS & $2 S L S$ & OLS & $2 S L S$ \\
\hline Trade & $\begin{array}{c}-0.015^{\star *} \\
(0.002)\end{array}$ & $\begin{array}{c}-0.020^{\star \star} \\
(0.002)\end{array}$ & $=$ & $=$ & $\begin{array}{l}-0.008 \\
(0.007)\end{array}$ & $\begin{array}{c}0.401 \\
(1.034)\end{array}$ \\
\hline FDI & - & - & $\begin{array}{c}-0.006 \text { ** } \\
(0.002)\end{array}$ & $\begin{array}{c}-0.014 \text { ** } \\
(0.003)\end{array}$ & $\begin{array}{l}-0.004 \\
(0.003)\end{array}$ & $\begin{array}{l}-0.226 \\
(0.546)\end{array}$ \\
\hline Constant & $\begin{array}{l}0.206 \text { ** } \\
(0.015)\end{array}$ & $\begin{array}{c}0.245 * * \\
(0.016)\end{array}$ & $\begin{array}{c}0.125 * * \\
(0.012)\end{array}$ & $\begin{array}{c}0.170 * * \\
(0.016)\end{array}$ & $\begin{array}{c}0.177^{* *} \\
(0.046)\end{array}$ & $\begin{array}{l}-1.948 \\
(5.461)\end{array}$ \\
\hline Adjusted $\mathrm{R}^{2}$ & 0.898 & - & 0.141 & - & 0.142 & - \\
\hline J Statistics & - & 1.05 & - & 0.51 & - & - \\
\hline Average First Stage F & & 2447 ** & & $225^{* *}$ & & $227^{* *}$ \\
\hline Number of Observations & 1050 & 1050 & 491 & 491 & 491 & 491 \\
\hline
\end{tabular}

** Significance at the 99-percent confidence level

Note:

The dependent variable is the measure of difference in consumption patterns between two countries, conditional on price and income. The explanatory variables, Trade and FDI, are defined by constant US dollars, in logarithm.

The standard error is inside a parenthesis.

For the two-stage least squared estimates are obtained by using as instruments, GDP and population. 


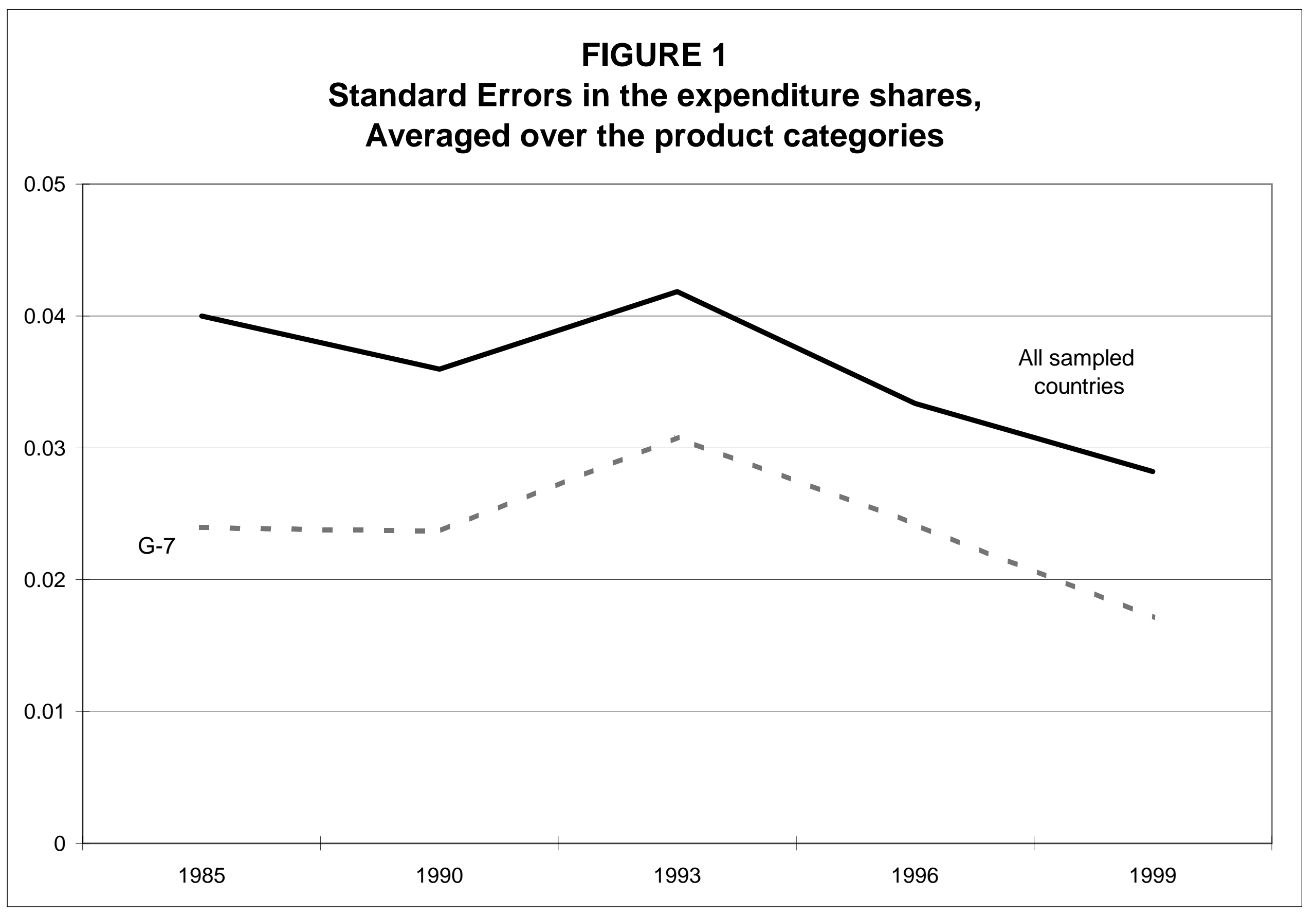

